\title{
Megaprojetos e ambiente urbano: Parâmetros para elaboração do relatório de impacto de vizinhança
}

\author{
Antônio Cláudio M. L. Moreira \\ Arquiteto, mestre e doutor pela FAUUSP, docente de \\ planejamento urbano e de habitação de interesse social do \\ curso de graduação da FAUUSP e docente de políticas \\ públicas ambientais urbanas no curso de pós-graduação \\ da FAUUSP
}

Este trabalho trata do impacto dos grandes edifícios do setor privado e das atividades neles instaladas sobre o ambiente urbano Resumo do município de São Paulo. Busca um conceito de ambiente urbano que possibilite identificar a natureza dos impactos ambientais urbanos e a extensão territorial destes impactos. Faz uma análise crítica dos critérios de identificação dos empreendimentos com potencial de significativa repercussão sobre o ambiente urbano. Faz também uma análise crítica dos relatórios de impacto de vizinhança apresentados no período 1990-1992. Conclui com uma proposta de parâmetros para a elaboração dos relatórios de impacto de vizinhança.

This is a study on the impact exerced on the urban environment of São Paulo City by large-scale buildings of the private sector, Abstract and by the activities therein. It looks for an urban environment concept that allows the identification of the nature and the territorial extension of urban environments impacts. It makes a critical analysis of the identification criteria of the developments with potential effects on the urban environment. It makes also a critical analysis of the reports of neighborhood impact presented between 1990-1992. In conclusion, it proposes parameters for the elaboration of neighborhood reports. 
Introdução Este trabalho trata do impacto de grandes empreendimentos imobiliários sobre o ambiente urbano. Tem por objeto os grandes empreendimentos edilícios do setor privado no município de São Paulo, submetidos à aprovação da prefeitura de São Paulo a partir da vigência da Lei Orgânica do Município (abril de 1990). Seu objetivo é estabelecer parâmetros para elaboração do Relatório de Impacto de Vizinhança. Para tanto, procede à análise crítica dos parâmetros utilizados para identificação dos empreendimentos de significativa repercussão ambiental, dos procedimentos utilizados para licenciamento e dos relatórios de impacto de vizinhança apresentados no período 1990/1992, na administração da prefeita Luiza Erundina.

Com o advento da Lei Orgânica do Município de São Paulo, em abril de 1990, os grandes empreendimentos imobiliários ficaram sujeitos à apresentação de um Relatório de Impacto de Vizinhança, bem como à discussão desse relatório com a população interessada - os vizinhos dos empreendimentos de significativa repercussão ambiental. Embora a elaboração de relatórios de impacto ambiental não seja novidade, o conhecimento acumulado sobre ambiente urbano ainda é muito pequeno, e o uso do relatório de impacto como instrumento de planejamento urbano ainda é novidade. Assim, a implementação da lei orgânica trouxe novas questões para os produtores dos grandes empreendimentos imobiliários e para os agentes públicos licenciadores destes empreendimentos, a saber: O que é ambiente urbano? O que é impacto ambiental? O que é relatório de impacto de vizinhança? 0 que é empreendimento de significativa repercussão ambiental? Qual é o conteúdo do relatório de impacto de vizinhança? Buscamos aqui dar respostas a estas questões.

Na busca de um conceito de ambiente encontramos fragmentos desse conceito: o ambiente aparece nos estudos do Clube de Roma (citado por Viola, 5) como presenvação de recursos naturais não renováveis; o ambiente aparece em Castells $(1983,230)$ como relações dos homens com a natureza; o ambiente aparece em Moraes $(1994,78)$ como manifestação dos processos sociais que organizam o acesso e o uso dos recursos da natureza; o ambiente aparece no Relatório Nosso Futuro Comum $(1988,9)$ associado ao desenvolvimento que preserva os recursos da natureza para as próximas gerações, denominado "ambiente sustentável" 
Estes conceitos não se excluem. Pelo contrário, eles se complementam e permitem a concepção do ambiente como relações dos homens com a natureza, constituídas pela apropriação e uso dos recursos naturais. Em particular o ambiente urbano compreende as relações do homens com a natureza, em aglomerações de população e atividades humanas, constituídas pela apropriação e uso do espaço construído e dos recursos naturais.

As relações de apropriação e uso dos recursos naturais presentes no ambiente urbano são explicadas pelo conceito de ecossistema. Um ecossistema compreende o conjunto das relações dos seres vivos com o meio físico, compondo fluxos de energia e ciclos de matéria, para nutrição e biodiversidade (Branco e Rocha, 1987, 20). No ambiente urbano, estes fluxos compreendem, entre outros, o abastecimento de água potável, de energia elétrica e de gás combustível; o escoamento de águas pluviais e o afastamento de esgotos sanitários; a circulação de informações, pessoas e mercadorias. Ainda no ambiente urbano estes fluxos compreendem a utilização do solo, do ar, da água e dos demais seres vivos quer como alimento, quer como insumo, quer como diluidor de resíduos, quer como dispersor de ruídos e calor.

As relações de apropriação e uso do espaço construído são explicadas pelos estudiosos do meio urbano ora como relações de acomodação da organização social ao meio físico (Park, citado por Gottdiener, 1985, 36), ora como processo de reprodução da força de trabalho (Castells, 1983, 21), ora como lugar da produção e circulação do capital (Lojkine, 1981, 21), ora como lugar de conflitos entre atores (Pacheco, 1992, 48-49). Mas essas abordagens não dão qualquer pista sobre a natureza das relações constituintes do ambiente urbano.

Considerando, porém, o campo de estudo específico dos urbanistas - o uso e a ocupação do solo urbanizado e construído, podemos entender estas relações como relações da população e das atividades humanas, organizadas pelo processo social, de acesso (apropriação) e fruição (uso e ocupação) do espaço urbanizado e construído.

Assim, entendemos como relações constitutivas do ambiente urbano: os fluxos de energia, matéria e informações, providos pelas redes de infra-estrutura urbana; assim como a apropriação 
e fruição (uso e ocupação) do espaço construído e dos recursos naturais - solo, ar, água, silêncio, clima e demais seres vivos que convivem com a população humana.

\section{Impacto ambiental}

\section{Relatório de impacto de vizinhança}

Empreendimento de significativa repercussão ambiental
Resolvida a questão do conceito de ambiente urbano, buscamos um conceito de significativo impacto sobre o ambiente urbano. Deixamos de lado o conceito oficial de impacto ambiental que o define como qualquer alteração da propriedade do meio ambiente, por ser excessivamente abrangente. Preferimos o conceito de impacto ambiental como uma poderosa influência que desequilibra um ecossistema, apresentado por Murguel Branco $(1984,57)$. Este conceito admite a capacidade de um ecossistema de absorver impactos até um limite, que quando ultrapassado o desequilibra. Assim, propomos o conceito de significativo impacto como qualquer alteração produzida pelos homens e suas atividades nas relações constitutivas do ambiente e que excedam a capacidade de absorção desse ambiente.

Buscamos ainda um conceito de relatório de impacto de vizinhança. Trata-se, por definição da lei orgânica, de um relatório sobre as repercussões significativas dos empreendimentos sobre o ambiente urbano. É, portanto, um relatório de impacto ambiental, e como tal está sujeito à regulamentação federal sobre a matéria, a saber: é obrigatório para os empreendimentos relacionados no artigo 2을 da Resolução CONAMA 01/86; seu conteúdo básico é a caracterização do empreendimento, o diagnóstico da área de influência e a avaliação de impactos significativos (Decreto Federal n. 99.274/94). Está ainda sujeito à regulamentação municipal sobre a matéria, a saber: a Secção 4.4 da Lei Municipal n. 11.228 de 26/ 06/92, e o Decreto Municipal n. 34.713/94.

Buscamos também um conceito de empreendimento de significativa repercussão ambiental ou de significativo impacto ambiental.

A partir de 1988, o novo Plano Diretor de Desenvolvimento Integrado define empreendimentos de grande efeito na área urbana, e para estes empreendimentos exige a elaboração de Relatório de Impacto sobre o Meio Ambiente - RIMA. Segundo a lei do plano diretor são empreendimentos de grande efeito na área 
urbana: os empreendimentos explicitados por norma federal, os grandes equipamentos referidos no artigo 10 desta lei, mais os equipamentos do sistema estrutural viário e de transporte coletivo, os conjuntos habitacionais acima de 400 unidades e as operações urbanas com área de intervenção acima de 10 hectares.

Além deste critério, a Prefeitura do Município de São Paulo, logo após a promulgação da lei orgânica, em abril de 1990, adotou informalmente, para identificação dos empreendimentos com potencial de significativo impacto ambiental o critério do porte dos empreendimentos e o parâmetro de mais de $20.000 \mathrm{~m}^{2}$ de área computável para empreendimentos não residenciais. Seu objetivo, na oportunidade era a maior acumulação de conhecimento para melhor definição, tanto dos critérios, como dos parâmetros de identificação dos empreendimentos de significativo impacto ambiental.

Decorridos dois anos e meio da promulgação da lei orgânica, a Regulamentação do Código de Obras e Edificações, em setembro de 1992, com base no conhecimento até então acumulado, definiu como empreendimentos de impacto ambiental os empreendimentos residenciais com área superior a $40.000 \mathrm{~m}^{2}$ computáveis e os empreendimentos não residenciais com área superior a $20.000 \mathrm{~m}^{2}$ computáveis (Decreto Municipal n. 32.329/92).

Decorridos mais 2 anos, em 1994, uma segunda regulamentação dos relatórios de impacto de vizinhança estabeleceu novas dimensões mínimas para identificação dos empreendimentos de impacto ambiental, a saber: $80.000 \mathrm{~m}^{2}$ de área computável para uso residencial; $60.000 \mathrm{~m}^{2}$ de área computável para comércio e serviços; $40.000 \mathrm{~m}^{2}$ de área computável para uso institucional; e $20.000 \mathrm{~m}^{2}$ de área computável para indústrias (Decreto Municipal n. 34.713/94).

E mais, esta segunda regulamentação dispensou da apresentação de relatório de impacto de vizinhança, os conjuntos residenciais de interesse social financiados pelo Fundo Municipal de Habitação e os empreendimentos que tenham parâmetros urbanísticos definidos pela Comissão Normativa da Legislação Urbanística CNLU (Decreto Municipal n. 34.713/94). Entretanto esta dispensa, definida por decreto, não se aplica aos empreendimentos de impacto a que se refere a lei do plano diretor. 


\section{Conteúdo dos Relatórios de Impacto de Vizinhança}

Em 1990, por ocasião da promulgação da Lei Orgânica do Município de São Paulo, ainda não havia suficiente experiência para definir o conteúdo dos relatórios de impacto de vizinhança. Nesta oportunidade o APROV sugeriu um roteiro de elaboração do relatório de impacto de vizinhança (Moreira, 1992).

Esse roteiro indicava os campos de estudo desse relatório, a saber: a repercussão do empreendimento sobre a paisagem urbana; sobre as atividades humanas instaladas; sobre a movimentação de pessoas e mercadorias; sobre a infra-estrutura urbana; e sobre os recursos naturais da vizinhança.

Indicava, também, os produtos finais do relatório de impacto de vizinhança, a saber: a demonstração da compatibilidade do sistema viário e de transportes com a quantidade de viagens geradas pelo empreendimento; a demonstração da compatibilidade do sistema de drenagem com o aumento do volume e da velocidade de escoamento de águas pluviais, gerado pela impermeabilização da área de intervenção; a demonstração da viabilidade de abastecimento de água, de coleta de esgotos, de abastecimento de energia elétrica; a indicação das transformações urbanísticas induzidas pelo empreendimento; a inserção da obra na paisagem.

A avaliação por APROV, organismo municipal encarregado do licenciamento dos empreendimentos edilícios de médio e grande portes, dos relatórios de impacto de vizinhança apresentados confirmou que o conteúdo sugerido era adequado à elaboração de relatórios de impacto ambiental dos grandes empreendimentos, e à avaliação dos eventuais impactos ambientais, desde que fosse acrescentado aos produtos finais a avaliação de impactos sobre os recursos naturais.

Essa avaliação forneceu ainda subsídios para a regulamentação da matéria, que ocorreu por ocasião da Regulamentação do Código de Obras e Edificações, ocorrida em setembro de 1992 (Decreto Municipal n. 32.329/92). Infelizmente, a redação deste decreto, não considerou toda experiência até então acumulada na elaboração e avaliação dos relatórios de impacto de vizinhança. Neste decreto constou apenas a exigência de demonstração de "medidas compatibilizadoras do empreendimento com a vizinhança relativamente à paisagem urbana, rede de serviços públicos e infra-estrutura". 
A segunda regulamentação do relatório de impacto de vizinhança, ocorrida em 1994 (Decreto Municipal n. 34.713/94), redefiniu seu campo de estudo. Desde então o seu conteúdo passou a ser, apenas, o fornecimento de dados necessários à análise da adequação do empreendimento às condições do local e da vizinhança, à análise das condições viárias da região e à análise das condições ambientais específicas do local e da sua vizinhança. Desde então a avaliação de impactos foi excluída do relatório de impacto de vizinhança, e em seu lugar esse relatório passou a conter apenas "dados"

Entretanto este procedimento está em desacordo com a legislação federal regulamentadora da matéria, que como já vimos define o conteúdo básico dos relatórios de impacto, a saber: a caracterização do empreendimento, o diagnóstico da área de influência e a avaliação dos impactos significativos.

No caso prevalecem os dois dispositivos: o decreto federal acima referido, que define o conteúdo básico do relatório de impacto ambiental e o decreto municipal que define os campos de estudo do relatório de impacto de vizinhança.

Assim delineados os conceitos de ambiente urbano, de impacto ambiental, de relatório de impacto de vizinhança, e de empreendimento de significativa repercussão ambiental, examinamos os relatórios de impacto de vizinhança apresentados no período 1990-1992 e disponíveis na biblioteca da Secretaria de Habitação e Desenvolvimento Urbano (SEHAB), para identificação das relações ambientais e da extensão territorial dos impactos ambientais considerados. Examinamos também os critérios utilizados pela Secretaria Municipal de Planejamento (Sempla) para identificação de impactos dos empreendimentos candidatos à operação interligada. (Azevedo Netto, 1984, e Wilderode, 1984)

No que diz respeito às redes de infra-estrutura, quase todos os relatórios examinados informaram sobre a existência de redes de água, esgotos, energia elétrica, drenagem de águas pluviais e telefonia nas vias públicas lindeiras. Faltou, entretanto, demonstrar que essas redes tinham capacidade para atender à demanda do empreendimento considerado.

Referente às vias e aos transportes públicos, quase todos os relatórios examinados informaram a demanda de viagens por

A Contribuição dos Relatórios de Impacto Apresentados 
veículos autônomos e por transportes coletivos nas horas de "pico" Faltou, entretanto, demonstrar que as vias e os transportes públicos existentes tinham capacidade para atender a demanda gerada pelo empreendimento.

Em relação à paisagem urbana, apenas 4 dentre os 27 relatórios examinados apresentaram uma avaliação consistente, e consideraram não impactante os empreendimentos cuja volumetria fosse similar à volumetria dos edifícios vizinhos. Faltou, entretanto, uma avaliação do significado do empreendimento para sua vizinhança. Para este fim seria útil a realização de audiências públicas para captar a interpretação dos vizinhos sobre a imagem e o significado do empreendimento e para orientar eventuais correções do impacto.

Quanto às transformações urbanísticas induzidas, apenas 4 dentre os 27 relatórios examinados apresentaram uma avaliação consistente, e consideraram não impactante os empreendimentos cuja atividade fosse similar às atividades vizinhas. Entretanto, este critério não é adequado para avaliar a compatibilidade de uma atividade humana com as atividades humanas vizinhas, porque uma nova atividade sempre disputa o mercado e os fornecedores das atividades já instaladas. Faltou conhecer as atividades vizinhas: a sua natureza, o seu porte, os seus fornecedores e a sua clientela.

No que diz respeito aos recursos naturais, apenas 5 dentre os 27 relatórios consideraram esta questão, mas abordaram apenas a geração de ruídos. Nesses casos esses relatórios de impacto de vizinhança concluíram pela inexistência do impacto, sem mencionar o nível de ruídos produzidos pelo empreendimento e o nível de ruídos no entorno. Para avaliação de impacto de um empreendimento sobre os recursos naturais - solo, ar, água, silêncio, clima e demais seres vivos que convivem com os homens nas aglomerações urbanas - é necessário conhecer a natureza e quantidade de efluentes do empreendimento, e compará-la com os parâmetros considerados suportáveis.

Referente a extensão da vizinhança, os relatórios de impacto de vizinhança avaliados trouxeram importantes contribuições.

Para as redes de serviços públicos, todos relatórios consideraram como área de influência de seus empreendimentos, pelo menos a 
extensão das vias públicas lindeiras aos empreendimentos. De fato, o impacto dos empreendimentos sobre os serviços públicos providos pelas redes de infra-estrutura se propagam indistintamente por toda rede atingida, na forma dos custos de adaptação daquela rede à nova demanda. A correção desse impacto não ocorre necessariamente nas imediações da ligação, mas nos pontos daquelas redes que possibilitam ampliar a capacidade do serviço no lugar em que tenha sido efetuada a ligação.

Para as redes de vias públicas, todos relatórios analisados consideraram como área de influência de seus empreendimentos, as vias públicas que dão acesso ao empreendimento. Mas um deles foi mais preciso: considerou como área de influência a extensão das vias de acesso ao empreendimento até os "nós" de tráfego mais próximos. Esta última nos parece mais adequada, pois o impacto do tráfego gerado por um empreendimento se propaga sobre as vias de acesso até os "nós" de tráfego, e destes para o sistema viário principal.

No caso do impacto sobre paisagem urbana e sobre atividades humanas da vizinhança, a maioria dos relatórios de impacto de vizinhança considerou como área de influência a quadra do empreendimento, mais as vias públicas lindeiras, mais os imóveis lindeiros a estas vias públicas. De fato, esta área recebe diretamente o impacto de um novo empreendimento. Mas as vias de acesso ao empreendimento, desde os "nós" de tráfego mais próximos também sofrem o impacto do tráfego de acesso ao empreendimento, que por sua vez provocam transformações nas atividades humanas e na paisagem urbana destas vias.

Para os fins de elaboração e avaliação de relatórios de impacto de vizinhança, entendemos o ambiente urbano, o conjunto das relações dos homens com a natureza, em aglomerações de população e atividades humanas, constituídas pela apropriação e fruição do espaço construído - as edificações e a infra-estrutura, bem como pelos dos recursos naturais remanescentes - solo, ar, água, silêncio, clima, demais seres vivos que convivem com a população humana. Para os mesmos fins entendemos como impacto ambiental qualquer alteração produzida pelos homens e suas atividades nestas relações constitutivas do ambiente, que exceda a capacidade de absorção desse ambiente. 
São empreendimentos de significativa repercussão ambiental:

- Os empreendimentos definidos no Decreto Federal n. 99.274/ 94 e relacionados no artigo $2^{\circ}$ da Resolução CONAMA 01/86;

- os empreendimentos edilícios de grande porte referidos no Decreto Municipal n. 34.713/94, cuja área computável exceda as seguintes dimensões: $80.000 \mathrm{~m}^{2}$ para empreendimentos residenciais; $60.000 \mathrm{~m}^{2}$ para empreendimentos de comércio ou serviço; $40.000 \mathrm{~m}^{2}$ para empreendimentos institucionais; $\mathrm{e}$ $20.000 \mathrm{~m}^{2}$ para indústrias;

- os empreendimentos públicos de grande porte definidos pela lei do plano diretor, a saber: os equipamentos do sistema estrutural viário e de transporte coletivo, os conjuntos habitacionais acima de 400 unidades e as operações urbanas com área de intervenção acima de 10 hectares;

- o parcelamento do solo, a ocupação de área de proteção dos mananciais, a ocupação da área envoltória de bens tombados, e as demais construções que independentemente de seu porte possam ter significativa repercussão ambiental, tais como as torres de transmissão de sinais de radiofreqüência e os grandes painéis para publicidade e propaganda.

O relatório de impacto de vizinhança tem por conteúdo mínimo a caracterização do empreendimento, o diagnóstico da área de influência e a avaliação de impactos significativos, conforme definido pelo Decreto Federal n. 99.274/94, abrangendo os campos de estudo definidos pelo Decreto n. 34.713/94.

Não obstante com base na experiência acumulada na elaboração e avaliação dos relatórios apresentados no período 1990-1992, entendemos que o relatório de impacto de vizinhança deve conter:

- A demonstração da compatibilidade do empreendimento com a capacidade das redes de infra-estrutura urbana, através de estudo de ligação realizado pelo agente público controlador do serviço ou pela concessionária do serviço público;

- a demonstração da compatibilidade do empreendimento com a capacidade das vias e do sistema de transportes públicos, através de estimativa de viagens geradas pelo empreendimento comparada com capacidade das vias e do sistema de transportes públicos; 
- a demonstração da compatibilidade do empreendimento com a paisagem urbana da vizinhança, por semelhança com as atividades humanas vizinhas e/ou com a volumetria dos edifícios vizinhos, e pela aquiescência da população e as atividades humanas vizinhas;

- a demonstração da compatibilidade do empreendimento com as atividades humanas vizinhas, por similaridade e por complementaridade com as atividades vizinhas;

- a demonstração da compatibilidade do empreendimento com os recursos naturais remanescentes da urbanização principalmente solo, ar, água, silêncio, clima e demais seres vivos que convivem com os homens nas aglomerações urbanas.

Com base ainda nesta experiência acumulada entendemos que a vizinhança pode, simplificadamente, ser reduzida a três diferentes áreas:

- A extensão das vias públicas que circunscrevem o empreendimento considerado, para avaliação de impactos sobre as redes de serviços públicos;

- a extensão das vias públicas que circunscrevem o empreendimento considerado e a extensão das vias de acesso até os "nós" de tráfego mais próximos, para avaliação de impactos sobre os sistemas viário e de transportes públicos;

- a quadra do empreendimento, mais as vias públicas lindeiras, mais os imóveis lindeiros a estas vias públicas, para avaliação de impactos sobre paisagem, sobre atividades humanas instaladas, e sobre os recursos naturais.

AZEVEDO NETTO, Domingos Theodoro. O jogo das interligadas: uma política pública em avaliação: a Lein. 10.209/86 do municipio de São Paulo. São Paulo, 1994. Dissertação (mestrado) - Escola de Administração de Empresas de São Paulo, da Fundação Getúlio Vargas - EAESP/FGV.

BRANCO, Samuel Murguel, ROCHA, Aristides Almeida. Elementos de ciências do ambiente São Paulo: Cetesb/Ascetesb, 1987.

BRANCO, Samuel Murguel. O fenômeno Cubatão na visão do ecólogo. São Paulo: Cetesb/ Ascetesb, 1984.

CASTELLS, Manuel. La question urbaine. Librarie Francois Maspero. Trad. de Arlene Caetano. A questão urbana. Rio de Janeiro: Paz e Terra, 1983.

GOTTDIENER, Marc. A produção social do espaço urbano. São Paulo: Editora da Universidade de São Paulo, 1993.

LOJKINE, Jean. O estado capitalista e a questão urbana. São Paulo: Martins Fontes, 1981.

\section{Bibliografia}


MACEDO, Silvio Soares. Paisagismo e paisagem. Paisagem e ambiente. São Paulo: FAUUSP, n. 5, 1994.

MAGNOLLI, Miranda Martinelli. Formação de recursos humanos e meio ambiente. Sinopses. São Paulo: FAUUSP, n. 1, p. 71-76, 1981. e 2, 1986 Ambiente, espaço e paisagem. Paisagem e ambiente. São Paulo: FAUUSP, n.1

MORAES, Antônio Carlos Robert. Meio ambiente e ciências sociais. São Paulo: Hucitec, 1994.

MOREIRA, Antônio Cláudio M. L . Relatório de Impacto de Vizinhança. Sinopses. São Paulo: FAUUSP, n.18, p. 23-25, 1992.

Relatório de Impacto de Vizinhança. Trabalho apresentado no SEMINÁRIO SOBRE RELATÓRIOS DE IMPACTOCOMOINSTRUMENTOS DEPLANEJAMENTOURBANO. Porto Alegre, PROPUR, 1992.

NOSSO FUTURO COMUM (Relatório Brundtland). Comissão Mundial sobre o Meio Ambiente e Desenvolvimento. Rio de Janeiro: Editora da Fundação Getúlio Vargas, 1988.

PACHECO, R. S. et al. Atores e conflitos em questões ambientais urbanas. Espaço \& Debates. São Paulo: NERU, n. 35, p. 46-51, 1992.

PELLEGRINO, Paulo. A paisagem possível. Paisagem e ambiente. São Paulo: FAUUSP, n. 3 , 1989.

VIOLA, Eduardo J. A problemática ambiental do Brasil (1971-1991): da proteção ambiental ao desenvolvimento sustentável. Polis. São Paulo, n. 3, p. 4-14, 1991.

WILDERODE, Daniel Julien Van. Desregulamentação urbana: as operaçōes interligadas. São Paulo, 1994. Dissertação (Mestrado) - Faculdade de Arquitetura e Urbanismo, da Universidade de São Paulo. 